\title{
Michel Foucault e o problema da racionalidade
}

\section{Michel Foucault and the problem of rationality}

Alyson Thiago Fernandes Freire ${ }^{65}$

\section{Resumo}

O presente artigo objetiva discutir a abordagem foucaultiana das formas de racionalidade enquanto uma importante atualização crítica do problema da racionalização das sociedades modernas. Desse modo, em sua primeira parte, o artigo se concentra nas principais premissas e cautelas metodológicas do uso do conceito de racionalidade no esquema teórico de Michel Foucault. Por último, exploro como o filósofo francês discorre sobre os vínculos históricos sociológicos entre racionalidade, poder e crítica.

Palavras-chave. Michel Foucault. Racionalidade. Racionalização. Teoria Social.

\section{Abstract}

The present article aims at a Foucaultian approach to the forms of rationality as an important critical update of the problem of the rationalization of modern societies. Thus, in its first part, the article focuses on the main premises and methodological cautions of using the concept of rationality without theoretical framework of Michel Foucault. Finally, I explores how the philosopher discuss about the links between rationality, power and criticism.

Keywords. Michel Foucault. Rationality. Rationalization. Social Theory.

65 Professor de Sociologia do Instituto Federal de Educação, Ciência e Tecnologia do Rio Grande do Norte (IFRN); ORCID: https://orcid.org/0000-0001-6673-6289; Email: alyson.freire@ifrn.edu.br. 
"A racionalidade do abominável é um feito da história contemporânea"

(FOUCAULT, 2006, p. 354).

\section{Introdução}

O tema da racionalização do mundo moderno é, certamente, uma das questões mais caras do pensamento sociológico clássico. Jurgen Habermas (2012, p.28), por exemplo, afirma que a sociologia clássica "seleciona os seus conceitos fundamentais talhados segundo o crescimento da racionalidade do mundo moderno". De fato, sua força heurística para estudar a modernidade e suas rupturas societárias ${ }^{66}$, tanto em termos comparativos quanto em termos das dinâmicas subjetivas da ação dos indivíduos, torna a racionalização um dos tópicos mais instigantes e profícuos da produção sociológica.

A sociologia contemporânea continua a empregar o conceito de racionalização, aplicando-o sobre novos campos de problemas, dos quais podemos citar: os laços de dependência entre o Holocausto e a administração racional da burocracia (BAUMAN, 1998), a generalização dos princípios organizacionais dos restaurantes de fast food (RITZER, 1993), os usos individuais e sociais do corpo (TURNER, 1996) e a experiência amorosa em tempos de internet (ILLOUZ, 2011). Não é por acaso, portanto, que alguns considerem a racionalização uma preocupação analítica de tamanha centralidade para a sociologia, que ela, inclusive, articularia uma matriz teórica própria na teoria social sobre a modernidade (MARTUCCELLI, 1999).

Essa é a tese do sociólogo chileno, Danilo Martuccelli, segundo a qual a sociologia da modernidade seria constituída por três grandes matrizes ${ }^{67}$, entre elas

\footnotetext{
${ }^{66}$ No entanto, importante destacar, quando consideramos a sociologia da religião de Max Weber, o mais notável dos sociólogos estudiosos da racionalização, esta não se resume à cultura moderna e ao ocidente. Para o sociólogo alemão, a racionalização é um processo mais amplo com significado "histórico-universal" para as sociedades humanas e os seus desenvolvimentos.

67 A primeira matriz é formada pelas teorias da diferenciação social de autores como Emile Durkheim, Talcott Parsons, Pierre Bourdieu e Niklas Luhmann. A segunda matriz é formada pelas teorias dos processos de racionalização, e inclui nomes como Max Weber, Theodor Adorno e Max Horkheimer, Norbert Elias, Michel Foucault e Jurgen Habermas. A terceira, e última matriz teórica, é aquela das abordagens da condição moderna cujos nomes mais significativos são Georg Simmel,
} 
a da racionalização. Para essa matriz teórica, o entendimento e a descrição da singularidade do desenvolvimento histórico da sociedade moderna, e de sua experiência sociocultural e política, passam, irremediavelmente, pela compreensão dos processos racionalizadores. Além de Max Weber, Theodor Adorno, Max Horkheimer, Norbert Elias e Jurgen Habermas ${ }^{68}$, Martuccelli inclui, entre os representantes da matriz teórica da racionalização, um nome, por assim dizer, mais exterior à sociologia, se tomarmos essa num sentido mais estrito: o do filósofo francês Michel Foucault.

Não é difícil enxergar nas descrições históricas e nas análises foucaultianas da formação e funcionamento das instituições disciplinares um retrato de uma sociedade modelada por processos racionalizadores. $\mathrm{O}$ isolamento da loucura e dos loucos, a experiência médica e da doença sob o olhar da clínica, a emergência do encarceramento penal e a organização do domínio médico jurídico da sexualidade trazem, em seu bojo, o tema da racionalização, isto é, de como uma sociedade se torna cada vez mais estruturada por saberes e práticas sociais que racionalizam, de maneira constitutiva, os mais diversos âmbitos da experiência do sujeito na vida social e consigo mesmo.

O próprio Foucault, num balanço de sua obra, inscreveu o seu trabalho na tradição de autores cuja preocupação fundamental consiste em compreender a cultura moderna a partir do problema do racionalismo, particularmente as relações entre racionalização e poder (FOUCAULT, 1995 p. 233).

Como podemos concluir, grosso modo, Foucault é um pensador para quem a racionalidade moderna continua a ser um importante problema sociológico, filosófico, ético e político. No entanto, ao o situarmos naquela matriz teórica da racionalização, é preciso perguntar: que diferenças, questões e contribuições sua análise da racionalidade aporta para a sociologia? Podemos considerar que Foucault

Erving Goffman, Alain Touraine e Anthony Giddens. Para maiores detalhes ver: MARTUCCELLI, Danilo. Sociologies de la modernité: L'itinéraire du XX siècle. Paris: Gallimard, 1999.

68 Não é objeto desse artigo discutir a validade e os problemas do esquema proposto por Martucelli. Porém, entre outros pontos problemáticos, pode-se ponderar, por exemplo, como um autor como Georg Simmel poderia muito bem estar presente em mais de uma matriz. Se pensarmos em seus estudos sobre a economia monetária, a tragédia da cultura, a divisão do trabalho e, mesmo a metrópole e a vida mental, eles, certamente, possuem uma forte dimensão analítica acerca dos processos de racionalização e reificação da cultura e vida moderna. 
atualiza o problema da racionalização da modernidade? Essas são as interrogações que movem este artigo.

Para buscar essas respostas, tomaremos como fio condutor o próprio olhar foucaultiano sobre sua obra e pensamento. Principalmente em textos e entrevistas do final da década 1970 e começo da década de 1980, Foucault se preocupou em realizar um balanço acerca do conjunto de seu trabalho de pesquisa. Em grande medida, esse balanço autocomprensivo empreendido por Foucault define-se por um movimento reflexivo, no qual o conceito de racionalidade possui lugar privilegiado, acerca dos pontos de encontro e afastamento quanto à tradição da filosofia crítica alemão e, também, quanto à atualidade do projeto do Esclarecimento. A partir do esforço de autocompreensão do autor sobre sua obra, podemos colher subsídios importantes para trazer à discussão a concepção foucaultiana de racionalidade, segundo o ângulo retrospectivo de sua própria avaliação.

\section{A racionalidade ocidental como problema}

Considerada em seu conjunto, a obra foucaultiana pode ser caracterizada como um esforço histórico-filosófico para compreender por que e como, no Ocidente, construímos complexos sistemas de práticas, com saberes e poderes variados, voltados a governar quase tudo o que dizemos, sabemos, fazemos e somos. Foucault intitula esse esforço de uma “ontologia histórica de nós mesmos". Nesse projeto, a história da razão, como história das relações constitutivas entre a produção do conhecimento, as formas de poder e as práticas de relacionamento ético do sujeito consigo mesmo, ocupa um lugar primordial, ainda que, costumeiramente, pouco atentado (FOUCAULT, 2014).

É nesse sentido que Foucault defende que o seu o trabalho não tem como objetivo o poder, o discurso ou uma história das instituições ou das ideias, "mas uma história da racionalidade, tal como ela opera nas instituições e na conduta das pessoas" (FOUCAULT, 2006, p. 319).

Para o filósofo francês, há uma racionalidade nos mais diversos aspectos e domínios das práticas humanas, e não apenas no âmbito do saber, senão também 
nas relações políticas, nas condutas, nas instituições, até mesmo nas formas mais violentas das práticas históricas há uma racionalidade. A despeito da irracionalidade que foi o nazismo, argumenta Foucault, trata-se de uma irracionalidade que era ao mesmo tempo, afinal, uma certa forma de racionalidade. 0 que não significa que a razão seja uma construção totalitária que terminou por se tornar o seu reverso, como escrevem Adorno e Horkheimer (1985) no início de sua obra mais conhecida, sobre o esclarecimento e seu princípio corrosivo de racionalidade.

Apreender a singularidade dessa racionalidade, no Ocidente, que é tão compatível com a violência, com o poder, com a dominação sobre a ação dos outros, constitui o coração do problema do empreendimento intelectual foucaultiano. E, referindo-se indiretamente à Max Weber e à Theodor Adorno e Max Horkheimer, "ninguém precisa esperar a burocracia e os campos de concentração para reconhecer a existência de tais relações” (FOUCAULT, 2006, p. 366).

Sem sacralizar nem demonizar a razão, o que Foucault busca realizar é a análise dos limites, perigos e efeitos históricos do tipo de racionalidade que condiciona, no âmbito de nossas práticas e pressuposições mais familiares, o que pensamos, fazemos e somos em nossa atualidade. É um caminho crítico para compreender as condições de possibilidade das maneiras de pensar e se comportar que são ainda as nossas

Em uma entrevista sobre sua formação teórica, Foucault se espanta como as discussões e pesquisas sobre a história da racionalidade moderna, na França ${ }^{69}$ e Alemanha70, acabam por se encontrar sob um problema similar: "Parece-me que aqui se coloca a mesma questão: o que ocorreu na história da razão e nas diferentes formas pelas quais se exerce esse domínio da razão?” (FOUCAULT, 2005a p. 315). Seu espanto se deve ao fato de o campo intelectual francês de sua época ter pouquíssimo conhecimento acerca de Max Weber e, menos ainda, sobre a Escola

\footnotetext{
${ }^{69}$ Foucault se refere à tradição epistemológica francesa de historiadores da ciência, como Gaston Bachelard, Georges Canguilhem, Jean Cavaillés e Alexander Koyré para os quais, segundo o autor de História da loucura, a história das ciências consiste na investigação de uma razão "cuja autonomia de estrutura traz consigo a história dos dogmatismos e dos depotismos..." (FOUCAULT, 2005b, p. 357).

${ }^{70}$ Foucault se refere aos trabalhos de Max Weber e da Escola de Frankfurt, notadamente Theodor Adorno, Max Horkheimer e Jurgen Habermas.
} 
de Frankfurt ${ }^{71}$. 0 que, segundo o filósofo, não impediu a convergência dessas duas tradições para uma mesma problemática, ainda que por caminhos diferentes.

Se, por um lado, Foucault reconhece que seu trabalho também se orienta pela tarefa de “destacar a forma de racionalidade que é apresentada como dominante e à qual se dá o status da razão" (FOUCAULT, 2005b, p. 316), por outro, isso não significa ausência de diferenças significativas. Para Foucault, o problema da razão deve ser abordado a partir das condições históricas e das formas de racionalidade em que o sujeito humano se torna ele próprio um objeto de saber e de governo possível: "O que me interessou... eram justamente as formas de racionalidade que o sujeito humano aplicava a si mesmo" (FOUCAULT, 2005b, p. 318).

Desse aspecto deriva um conjunto de proposições teórico-metodológicas que caracterizam a especificidade do tratamento analítico foucaultiano com respeito à racionalidade e à racionalização das sociedades ocidentais.

\section{A abordagem foucaultiana da racionalidade e da racionalização}

Entre as contribuições teóricas da obra foucaultiana está, certamente, a elaboração e aplicação de uma concepção relativa e plural de racionalidade.

De partida, é importante destacar, que racionalidade significa algo diferente de um atributo cognitivo do sujeito ou um conceito constitutivo de uma teoria da ação e do processo histórico (WEBER, 1994; 1999; GIDDENS, 2003; BOUDON, 2009). No pensamento foucaultiano, "racionalidade é o que programa e orienta o conjunto da conduta humana" (FOUCAULT, 2006, p. 319).

A definição por si só exprime seu vínculo íntimo com o poder. Como, para Foucault, as relações de poder funcionam como modos de ação sobre um campo de possibilidades (FOUCAULT, 2014, p. 137), o exercício de poder implica uma série de sistematizações e orientações para que ele possa ter alguma eficácia e estabilidade.

\footnotetext{
${ }^{71}$ Ao avaliarmos pelas primeiras traduções francesas dos trabalhos de Adorno e Horkheimer, assim como os de Habermas, a Teoria crítica aportou na França a partir da década de 1970 (HONNETH, 2009).
} 
Foucault elenca algumas dessas racionalizações que as relações de poder necessitam para o seu funcionamento, as quais o pesquisador que queira analisá-las deve se atentar: 1) 0 sistema de diferenciações que permitem agir sobre a ação dos outros; 2) 0 tipo de objetivos perseguidos pelos que agem sobre a ação dos outros; 3) As modalidades instrumentais pelos quais o exercício do poder atua sobre os indivíduos; 4) As formas de institucionalização (FOUCAULT, 2014, p.136).

Ou seja, as relações poder, em suma, põem em movimento formas de racionalidade e racionalização. A multiplicidade de modos pelos quais as ações humanas podem ser induzidas, estruturadas e correspondidas - assim como a diversidade dos focos sobre os quais se pode agir sobre - redunda na tese de que não pode haver um tipo único de racionalidade, mas uma pluralidade de racionalidades. Cada uma delas relacionada a um sistema de práticas históricas, a um modo de agir sobre e governar a ação dos outros. Portanto, racionalidade, em Foucault, tem a ver com a multiplicidade de lógicas singulares de práticas institucionais históricas construídas num contexto determinado. Essas práticas podem ser práticas administrativas, jurídicas, penais, médicas, pedagógicas, éticas etc..

Disso resulta um segundo ponto fundamental: não considerar como um todo a racionalização da sociedade e da cultura, "mas analisá-la como um processo em vários campos; cada um dos quais com uma referência a uma experiência fundamental: loucura, doença, morte, crime, sexualidade" (FOUCAULT, 1995, p. 233).

Em vez do processo de racionalização geral ou suas tendências de desenvolvimento, analisar racionalidades específicas, isto é, as formas históricas de interdependência entre saber, poder e verdade. As formas de racionalidade e os graus de racionalização variam de acordo com o campo de experiência, as tecnologias de poder e os saberes em que são empregadas, de sorte que a eficácia dos resultados e os custos implicados são, também, variáveis e relativamente instáveis (FOUCAULT, 2014, p. 137).

Teoricamente, as formas de racionalidade organizam, nos regimes de práticas, 1) o campo de objetos e sua produção, isto é, instituições, tipos de 
sujeito, conceitos, regras etc., e 2) o campo de possibilidades de ação dos indivíduos, isto é, as táticas e estratégias de poder, as técnicas, as resistências e enfrentamentos. Desse modo, racionalidade é abordada como um conceito com "um sentido instrumental e relativo" (FOUCAULT, 2012, p. 335).

Nesse sentido, como conceito, a racionalidade interessa menos pelos seus sentidos e direções e mais porque ela auxilia a sistematização de um conjunto heterogêneo de fatores atuantes e distintos nas práticas históricas, isto é, o funcionamento, os fins perseguidos, os efeitos gerados, os meios e as estratégias empregados, os usos e as inter-relações das práticas sociais num contexto determinado. Para Foucault, a descrição e a análise de todos esses fatores, num regime historicamente determinado de práticas sociais, permitem a articulação das formas particulares de racionalidades empregadas. Sob esse prisma, podemos conceber o projeto intelectual foucaultiano como um projeto de uma história das formas de racionalidade das práticas humanas de sujeição e subjetivação.

A atenção de Foucault acerca do problema da racionalidade moderna recobrirá, sobretudo, os laços desta com o exercício do poder, de modo que o inter-relacionamento entre formas de racionalidade e estruturas políticas e institucionais é alçado a uma dimensão fundamental para se entender as especificidades das relações de dominação no ocidente. Assim como Max Weber e Theodor Adorno, Foucault concorda que, nas sociedades ocidentais modernas, a racionalidade não é apenas um princípio teórico e de procedimentos científicos. Ela é, com efeito, um tipo de prática social, estreitamente ligada a vínculos muito complexos e circulares com as formas de poder de nossas sociedades (FOUCAULT, 1982, p.47).

Por exemplo, vejamos, em maiores detalhes, como a análise da racionalização aparece em Vigiar e Punir.

Nesse livro, Foucault analisa diversos mecanismos de poder e de assujeitamento que tomam os indivíduos como objetos de correção, avaliação, produção e utilização: a vigilância, a sanção normalizadora e o exame. São técnicas de poder inscritas numa variedade de regimes de práticas sociais (educativas, militares, penais, econômicas), e cujo funcionamento, os fins, os efeitos e as inter- 
relações objetivam uma racionalidade singular de gestão e ajustamento dos homens, uma "anatomia política”. Essa racionalidade consiste em definir "como se pode ter domínio sobre o corpo dos outros, não simplesmente para que façam o que quer, mas para que operem como se quer, com as técnicas, segunda a rapidez e a eficácia que se determina” (FOUCAULT, 2004, p. 119).

Mais do que simplesmente uma genealogia do encarceramento penal como modelo punitivo dominante, Vigiar e Punir é uma investigação detalhada da racionalização das técnicas de poder incidentes sobre o corpo individual. Quando Foucault examina essa forma de poder que busca "um controle minucioso das operações do corpo", uma "sujeição constante de suas forças" e impor sobre eles “uma relação de docilidade/utilidade", ele descreve uma forma de racionalidade específica das sociedades europeias do século XVIII e XIX empregada em seu regime de práticas penais (FOUCAULT, 2004, p.126).

Por isso Foucault diz que tema fundamental tratado em Vigiar e Punir não é a delinquência nos séculos XVIII e XIX, nem as prisões na França entre 1760 e 1840, mas sim algo mais tênue: o tipo de cálculo, a ratio que foi posta em prática na reforma do sistema penal nesse período, a qual não se encerra nas instituições prisionais, pois se espalha, não sem modificações, pelo tecido social. Dito de outro modo, a forma de racionalidade empregada que ajudou a organizar um conjunto de dispositivos de poder sobre o corpo individual. A disciplinarização significa, na verdade, a aplicação e o funcionamento de uma racionalidade individualizante e corretora das condutas em que "se procurou um ajustamento cada vez mais controlado - cada vez mais racional e econômico - entre as atividades produtivas, as redes de comunicação e o jogo das relações de poder". Esse é o objeto principal de análise do livro, quer dizer, investigar essa intenção reflexiva e ímpeto prático (racionalidade), nas sociedades ocidentais modernas, de que um poder como o poder disciplinar seria possível e desejável (FOUCAULT, 2014 p. 131).

Os conceitos gerais e abarcadores de racionalização ou razão instrumental acabam por homogeneizar e igualar, em suas características e singularidades, racionalidades e processos específicos, como por exemplo, o internamento administrativo dos loucos, “vagabundos", “miseráveis" e "salteadores" no século 
XVII e o encarceramento disciplinar dos criminosos e delinquentes no século XIX. Nesses dois casos históricos, temos lógicas sociais e racionalidades distintas. No primeiro, trata-se mais da reclusão para excluir e apartar ao passo que, no segundo, a reclusão para punir, corrigir, normalizar e reinserir

Não é exagero afirmar que Foucault desenvolve uma história da razão. Não uma história da razão que se pergunta e analisa o seu processo geral, sua odisseia na cultura ocidental ao longo dos séculos rumo a uma reconciliação final da razão consigo mesma. Mas a história das formas diversas e diferenciadas da razão: "razão punitiva”, "razão médica”, "razão estatal”. O problema da razão é abordado em função de cortes históricos, espaciais e epistemológicos, quer dizer, submetido a um tratamento investigativo regional e em domínios específicos de práticas sociais e saberes em que as diferentes formas de emprego e aplicação da racionalidade são analisadas em seus componentes discursivos e não-discursivos concretos:

A cerimônia dos suplícios públicos não é mais irracional em si do que o aprisionamento em uma cela; mas ela é irracional em relação a um tipo de prática penal que fez aparecer uma nova maneira de alcançar, através da pena, determinados efeitos, de calcular sua utilidade (FOUCAULT, 2012, p. 335).

Não as estruturas universais da razão, mas os acontecimentos e invenções sócio-históricas que, na forma de discursos, enunciados, técnicas de poder e instituições sociais, conformam as formas de racionalidade - a racionalidade psiquiátrica, clínica, jurídico médica, pedagógica, sexual, política - que afeiçoaram nossas pressuposições culturais e práticas sociais cotidianas com a fisionomia e familiaridade que elas vieram a possuir no presente.

Mais do que os sentidos da racionalização como processo, o que podemos concluir é que o interesse de Foucault, nessa problemática, é, antes, em como as formas de racionalização se inscrevem nas práticas sociais, quais efeitos geram e que papel desempenham nelas:

quais são os laços, quais são as conexões que podem encontrar-se entre mecanismos de coerção e elementos de conhecimento, que movimentos de reenvio e apoio se criam de uns para os outros, o que é que leva a que um dado elemento de conhecimento possa assumir efeitos de poder, num sistema como esse, a um elemento verdadeiro ou provável ou incerto ou 
falso, e o que é que leva a que um dado procedimento de coerção adquira a forma e as justificações próprias de um elemento racional, calculado, tecnicamente eficaz, etc. (FOUCAULT, 2012, p. 67). 


\title{
Racionalidade como problematização
}

Esta concepção de racionalidades múltiplas e específicas, historicamente localizáveis no espaço e tempo, não é parte de uma teoria explicativa geral em torno da generalização sociológica de um tipo particular de ação social - racional, instrumental, comunicativa. Ela constitui, antes, uma ferramenta de investigação dos diferentes modos de constituição de nossa existência a partir daquilo que Foucault nomeou como "problematização", isto é, a interrogação histórica sobre como um objeto ou um conjunto de relações específicas da experiência e do ser se tornaram um problema para o pensamento mediante práticas discursivas e práticas não-discursivas. A análise das racionalidades auxilia, como ferramentas de investigação, a traçar as formas assumidas e as práticas pelas quais se articularam os discursos na problematização de um campo de experiências possíveis.

Interpretando sua obra sob essa perspectiva das problematizações ${ }^{72}$, escreve Foucault:

\begin{abstract}
Problematização da loucura e da doença a partir de práticas sociais e médicas, definindo um certo perfil de 'normalização'; problematização da vida, da linguagem e do trabalho em práticas discursivas obedecendo a certas regras 'epistêmicas'; problematização do crime e do comportamento criminoso a partir de certas práticas punitivas obedecendo um modelo 'disciplinar'. Gostaria de mostrar, agora, de que maneira, na Antiguidade, a atividade e os prazeres sexuais foram problematizados através de práticas de si, pondo em jogo os critérios de uma estética da existência (FOUCAULT, 1984, p. 15-6).
\end{abstract}

Nota-se, como essa concepção matizada de racionalidade, unida ao conceito de problematização, resulta, por suas próprias características, torna viável e estimula um sem número de investigações empíricas, porque se apoia, por assim dizer, em teorias regionais e de médio alcance sobre regimes de práticas, com suas relações de poder e dominação, determinadas e peculiares.

\footnotetext{
72 O conceito de problematização serve ainda a Foucault para demarcar a singularidade do seu projeto de uma história do pensamento em oposição a outras formas de história: “E, afinal, é esta a tarefa de uma história do pensamento por oposição à história dos comportamentos ou das representações: definir as condições nas quais o ser humano 'problematiza' o que ele é, e o mundo no qual ele vive" (FOUCAULT, 1984, p. 14).
} 
Foucault anima um entendimento profundamente empírico e operatório de "racionalidade", ou seja, enquanto ferramenta de investigação, e não como teoria explicativa de processos históricos gerais. Sem com isso, vale ressaltar, se fechar na própria descrição das práticas e das formas de emprego da racionalidade histórica e socialmente determinadas. Ora, Foucault é um filósofo com profunda ambição teórica e explicativa para se limitar a este ponto. Evita-se, sim, prudentemente, o diagnóstico epocal e totalizador.

Analisado sob esse ponto de vista, a fecundidade do modelo analítico foucaultiano para a investigação social explica-se, entre outras razões, exatamente por esta concepção pluralista e heterogênea de racionalidade. Esta é, sem dúvida, uma das razões pelas quais o "efeito Foucault" alcançou e se alastrou por tantos campos do saber científico e teórico contemporâneo, porque dita noção de racionalidade enquanto regime de práticas, técnicas e discursos diversos instila a abertura ao estudo e à investigação dos mais diversos domínios da ação social, quer no presente quer no passado.

Segundo, por investigar o racionalismo ocidental moderno, Foucault não entende o mesmo que Adorno e Horkheimer em Dialética do Esclarecimento. Os pensadores alemães interessaram-se em iluminar a lógica subjacente do desenvolvimento epocal e ambivalente da racionalidade dominante na civilização ocidental. Materializada no progresso técnico, na ciência moderna e na organização econômica capitalista da sociedade burguesa, a racionalidade ocidental, para Adorno e Horkheimer, revela-se como uma razão instrumental, isto é, definida e orientada mais pelo cálculo eficiente dos meios para o controle da natureza e da subjetividade do que pela reflexão e questionamento sobre o valor e sentido das finalidades da ação social para o bem-estar e a autonomia humana (ADORNO \& HORKHEIMER, 1985).

Ao estudar a racionalidade das relações de dominações, Foucault não está interessado numa lógica subjacente nem na revelação de um princípio dialético único e epocal. Por isso, escreve: “tentei estabelecer interrelações, e não isomorfismo" (FOUCAULT, 2005b, p. 327). 
Os pontos de aplicação do racionalismo ocidental moderno que interessam a Foucault recaem sobre os corpos humanos, suas condutas, prazeres e emoções, e não apenas sobre a natureza ou a subjetividade entendida de maneira genérica. Trata-se, de um modo bastante empírico, de observar as formas de racionalidades delineadas pelas práticas sociais que incidem sobre 0 corpo do operário, da criança, do aluno, do interno, das mulheres, dos homossexuais, porque é aí que o poder se investe, na pele dos indivíduos, moldando seus gestos, suas atitudes, seus discursos, suas experiências, sua vida cotidiana. E, assim, como cada um desses corpos são um tipo de corpo, inserido numa situação estratégica específica e alvo de formas de saber/poder singulares que agem para vergar, produtivamente, estes corpos em algo mais do que matéria orgânica, também, em segundo lugar, são igualmente diversos os princípios de emprego que regem as racionalidades empregadas para sujeitar e objetivar os indivíduos como domínios de conhecimento e como sujeitos a determinadas formas de identidade, classificação e categorização.

Desse modo, em vez de uma racionalidade linear, temos regimes de racionalidades multilineares, os quais, cumpre lembrar, não obedecem lógicas preestabelecidas nem derivam da superação constante de irracionalidades precedentes ou de um processo sistêmico global e suprahistórico. Elas são acontecimentos históricos que surgem em substituição não-premeditada e nãoplanejada de formas de racionalidades anteriores em virtude de mudanças diversas no âmbito das relações de força e das práticas discursivas. As formas de racionalidade não possuem, com efeito, nem origem nem fim, de modo que, por isso, a história da razão, em Foucault, permanece aberta à dispersão e às reviravoltas dos acontecimentos discursivos e da transformação histórica. A racionalidade do poder, afirma Foucault, "é a das táticas muitas vezes bem explícitas no nível limitado em que se inscrevem que, encadeando-se entre si, invocando-se e se propagando, encontrando em outra parte apoio e condição, esboçam finalmente dispositivos de conjunto" (FOUCAULT, 1988, p. 91).

Um questionamento pertinente: como unificar os diferentes regimes de práticas e racionalidades? Quer dizer, como, então, obter alguma unidade ou 
estabilidade que permita articular a situação estratégica dominante ou global a partir da pluralidade das formas de racionalidade?

\section{Racionalidade como mediação}

Com o conceito de racionalidade, Foucault almeja, entre outras coisas, analisar como a dominação dos homens entre si funciona por meio daquilo que eles, sem o saberem ou controlarem por completo, inventam, em termos de técnicas, mecanismos, conhecimentos, no decorrer do acontecer social anônimo. $E$, nada disso encontra-se necessariamente num puro caos, disperso e pulverizado, de impossível concatenação e articulação de suas causas, motivações e meios pelo pensamento metódico. A ideia de racionalidade implica por si só um grau de sistematicidade e coerência entre ações, meios e fins, que é possível, em tese, reconstruir e articular conceitualmente. O que não significa que nas formas de racionalidade prepondere alguma teleologia ou uma intencionalidade por trás do devir histórica, "uma mão invisível da vontade de poder". Contudo, não é o conceito de racionalidade que resguarda Foucault contra a dispersão absoluta da multiplicidade e heterogeneidade das práticas de poder, mas o conceito de dispositivo.

O conceito de dispositivo, utilizado com mais consistência em A vontade de saber, torna possível sistematizar a multiplicidade das correlações de força e dos acontecimentos discursivos - os enunciados. Em outras palavras, promove a articulação dos domínios de saber, e seus enunciados, com as modalidades de exercício do poder, com suas técnicas e mecanismos. A articulação do binômio saber/poder permite, com efeito, a apreensão da racionalidade estratégica concernente e constituinte do campo de experiências possíveis.

A definição por si só esclarece: por dispositivo, Foucault entende:

[...] um conjunto decididamente heterogêneo que engloba discursos, instituições, organizações arquitetônicas, decisões regulamentares, leis, medidas administrativas, enunciados científicos, proposições filosóficas, morais, filantrópicas. Em suma, o dito e o não dito são os elementos do dispositivo. O dispositivo é a rede que se pode estabelecer entre estes elementos (FOUCAULT, 1979a, p. 244). 
Em um mesmo dispositivo, pode se operar diferentes racionalidades estratégicas. Desse modo, a racionalidade médica sobre a sexualidade vitoriana, por exemplo, pode ser observada, coletada e analisada a partir de uma heterogeneidade de práticas, tais como: discursos com pretensão de cientificidade sobre os perigos e segredos do sexo, as instituições médicas diversas, os regulamentos, fichas de consultas, prontuários médicos, relatórios psiquiátricos e diagnósticos terapêuticos, catálogos e classificação de patologias, estudos de caso, ementas, tipos de tratamento, instrumentos médicos.

É nessa multiplicidade e heterogeneidade que o poder se exerce, circula e funciona. Daí a fórmula foucaultiana de que o poder se exerce numa espécie de rede - o dispositivo. Os nós dessa rede são formados pelos mecanismos de poder, os enunciados e categorias de saberes que atuam no real e nos corpos com o objetivo de produzir e organizar ideias, conceitos, ações, gestos por meio da incitação, do incentivo, do fazer falar, do modelar, do suscitar em vez de com o objetivo de controlar as forças por meio da censura, da interdição, da proibição, inibição, da repressão.

O conceito de dispositivo faz com que Foucault, de uma só vez, lance luz sobre as formas ou tipos de racionalidade que a multiplicidade dos poderes e saberes ensejam, como também promove, por outro lado, um enraizamento empírico e social dessas racionalidades, escapando, assim, dos apelos metafísicos e trans históricos da razão instrumental e das tendências históricas ou civilizatórias globais. No esquema teórico foucaultiano, racionalidade é contextual e situada; ela é enraizada não nos atributos dos agentes sociais ou se expressa simplesmente nas características típicas da ação social, mas sim em condições discursivas e em relações de forças que Foucault procura articular teoricamente através de conceitos diferentes: “formação discursiva”, “dispositivo”, "relações entre saber e poder”, "regimes de verdade”, “jogos de verdade”.

Retomando, a noção de dispositivo é um recurso heurístico utilizado para conferir à multiplicidade das práticas sociais e à heterogeneidade dos enunciados uma inteligibilidade para a análise da situação estratégica e suas formas de racionalidade particulares. Dito de outro modo, o conceito de dispositivo funciona 
como uma mediação teórica entre a descrição das práticas históricas aplicadas existentes num nível micro e a articulação da situação estratégica mais ampla num nível macro (acumulação do capital, maximização da força de trabalho, integração das populações aos sistemas produtivos, gestão política do corpo social, entre outras). A mediação desses dois níveis permite a identificação das racionalidades em questão.

Por exemplo, a descrição das práticas de governo do Estado moderno, entre a metade do século XVIII e o século XIX, mostra não apenas como um conjunto de fenômenos próprios à vida biológica, mortalidade, natalidade, salubridade, entre outros, foram integrados aos cálculos da administração pública e as suas preocupações políticas. Mas sim uma mudança em termos de racionalidade política do exercício de poder em sua adequação a uma situação estratégica de industrialização e explosão demográfica.

Não se trata mais do esquema organizador da soberania, centrado no poder de vida e morte sobre os corpos dos súditos, nem apenas das tecnologias de vigilância e disciplinamento sobre corpo individual. As práticas governamentais modernas delineiam uma racionalidade política cuja principal característica é a regulamentação da vida dos indivíduos enquanto multiplicidade, como "população". Quer dizer, como uma "massa viva" a que o Estado deve conhecer, manter saudável e maximizar em suas forças vitais de conjunto, inclusive exercitando sobre ela, isto é, sobre as populações do corpo social, um poder de eliminação: "são mortos legitimamente aqueles que constituem uma espécie de perigo biológico para os outros" (FOUCAULT, 1988, p. 130).

A apreensão do funcionamento dessa racionalidade biopolítica, centrada em mecanismos racistas de "fazer viver" e "deixar morrer", é o elemento teórico de articulação das práticas governamentais com a situação estratégica global das sociedades europeias ao longo do século XIX, ou seja, a produção e acumulação de riquezas e a expansão e defesa do poder político da nação (FOUCAULT, 1999).

Portanto, o nexo que une dominação e racionalidade, em Foucault, não é pensado mediante o predomínio de uma forma de orientação da ação social 
enquanto tendência de desenvolvimento histórico civilizatório de uma cultura, como podemos observar nas análises de Max Weber acerca do "racionalismo de dominação do mundo" e a legitimidade política da dominação de tipo legal racional como o fundamento das formas de administração no mundo moderno (WEBER, 2001; 1994). Também não se trata de conceber esse nexo a partir de um olhar voltado a identificar e criticar "as patologias sociais" que cindiriam a coesão social e moral da sociedade e de seus compartimentos ou que bloqueariam a razão e a emancipação humana. Na versão habermasiana, os efeitos nocivos das ingerências que um tipo de racionalidade, a sistêmica e estratégica, pode exercer ao se sobrepor e colonizar o "mundo da vida", definido pela racionalidade interativa e comunicativa, o lócus da realização das relações morais e dialógicas na forma de direitos e deveres.

No esquema teórico foucaultiano, racionalidade e dominação estão referidos a domínios e regimes de práticas específicos e concretos, e, por isso, articulam-se de diversos modos a depender dos contextos de ação, das condições de emergência e formação desses contextos, das tecnologias políticas empregadas etc.. 0 que o nexo teórico entre racionalidade e dominação revela são os diferentes dispositivos, as formas de problematização singulares, as relações interdependentes entre saber e poder, os regimes de verdade provisórios que se consolidam, não sem luta, resistência e ambiguidades, em campos de experiência possíveis e diversos das relações humanas, constituindo diferentes e múltiplas formas de dominação.

Em síntese, a dominação não é pensada em chave única e a racionalidade, longe de explicitar os fundamentos de uma formação social, exprime a complexidade e a heterogeneidade do social. A nosso ver, especialmente em sociedades caracterizada por uma complexa e cada vez maior diferenciação social dos mundos institucionais e individualização dos modos de ser, Foucault oferece uma noção de racionalidade indispensável para qualquer sociologia da dominação das sociedades modernas e contemporâneas. 


\section{Crítica e racionalidade}

A centralidade dada por Foucault, em seus escritos genealógicos, ao papel da dominação na estruturação e rumos da vida social e dos processos históricos pode conduzir, por vezes, a uma inflação da perspectiva estratégica ${ }^{73}$. 0 que, por conseguinte, o faz flertar ou ser vítima de uma leitura que identifica uma subtração e minimização arbitrária e unilateral de outros aspectos da ação social e dos processos históricos, particularmente aqueles ligados ao incremento das capacidades criativas e de exercício da crítica dos agentes e das instituições (universidade, esfera pública, intelectuais, artistas) contra as normas existentes e suas pretensões de validade.

Esse é um dos flancos da crítica de Habermas ${ }^{74}$ (2002) e Honneth ${ }^{75}$ (2009) ao pensamento de Foucault. Para ambos, o filósofo francês engessou e encerrou os processos históricos e a ação social no âmbito dos imperativos funcionais e estratégicos de reprodução material e institucional da sociedade, perdendo de vista a outra faceta da racionalização e da modernidade, a qual, para Habermas, implicou em ganhos substantivos de liberdade e autonomia, especialmente relação a concepções religiosas estreitas e coercitivas. Trata-se da autonomização das esferas de valor (artes, ciência, ética) em que predomina a racionalidade

\footnotetext{
73 Dessa maneira, a formação das ciências humanas ou as propostas humanistas de reformas das sentenças penais no lluminismo são interpretadas unicamente sob o signo da vontade de poder e saber, e, desse modo, apenas contribuem, por seus efeitos, para o aperfeiçoamento na sucessão dos sistemas de dominação, pois: "A humanidade não progride lentamente, de combate em combate, até uma reciprocidade universal, em que as regras substituiriam para sempre a guerra; ela instala cada uma de suas violências em um sistema de regras, e prossegue assim de dominação em dominação" (FOUCAULT, 1979b p.25).

74 Para Habermas, as análises genealógicas de Foucault caem em aporias de duas ordem: 1) "reducionismos metodológicos", em que o poder penetra em todas possibilidades da experiência, inclusive a da resistência, e 2) "contradições performativas", onde o discurso que nega a possibilidade de racionalidade comunicativa ao mesmo tempo supõe ou considera dotado de validade o seu próprio discurso crítico contra a racionalidade comunicativa. Para maiores detalhes ver: HABERMAS, Jurgen. O discurso filosófico da modernidade. São Paulo. Martins Fontes, 2002.

${ }^{75}$ Para Honneth, o pensamento de Foucault padece do mesmo déficit sociológico, do reducionismo funcionalista e das aporias performativas na crítica da razão, já observados nas análises de Adorno e Horkheimer em A Dialética do Esclarecimento. Na crítica ao filósofo francês, Honneth acrescenta ainda $o$ que ele qualifica como compreensão behaviorista da relação sociedade e subjetividade/personalidade e a cegueira quanto aos progressos morais e legais da modernidade em termos de liberdades individuais, políticas e sociais. Para maiores detalhes ver: HONNETH, Axel. Crítica Del Poder: Fases en la reflexión de uma Teoria Crítica de la sociedad. Madrid: Machado, 2009.
} 
comunicativa, e não a instrumental estratégica movida pelo princípio do lucro, do desempenho e do exercício do poder (HABERMAS, 2002; HONNETH, 2009).

Habermas está correto. Porém, somente se nos limitarmos a uma leitura restrita da obra de Foucault, isto é, de seus escritos genealógicos mais consagrados, Vigiar e Punir e A Vontade de Saber. Não é verdade que Foucault passe ao largo da "autonomização das esferas de valor" e dos processos de desenvolvimento e institucionalização da crítica enquanto um dos traços definidores da modernidade.

Numa conferência de 1978, chamada "O que é a crítica?", ele traça a genealogia, no ocidente, do que intitula de "atitude crítica" (FOUCAULT, 1990). Nesse pequeno texto, o filósofo francês trata da emergência, entre o século XV e $\mathrm{XVI}$, de "uma certa maneira de pensar, de dizer, de agir igualmente, uma certa relação com o que existe, com o que se sabe, o que se faz, uma relação com a sociedade, com a cultura, uma relação com os outros também, e que se poderia chamar, digamos, de 'atitude crítica'” (FOUCAULT, 1990, p. 1-2).

Foucault percorre um caminho possível, entre outros, ele ressalta, da história desse tipo de atitude. Ele relaciona o aparecimento e desenvolvimento da "atitude crítica" com a diversificação e expansão do que chamou de "artes de governar" a partir do século XV. De acordo com Foucault, durante a Idade Média vigorou uma "arte de governar os homens" baseada na ideia de "direção espiritual", a chamada pastoral cristã. Conforme esta, para ser conduzido até a salvação, o indivíduo deveria deixar-se governar por completo ao longo do curso de sua vida, respeitando e obedecendo a autoridade do dogma das Santas Escrituras e às autoridades eclesiásticas tal como especificava a Igreja. A confissão e o "exame de consciência" constituíam as principais tecnologias de poder que ajustavam, na identidade mesmo do indivíduo, sua condução espiritual segundo os dogmas e autoridades religiosas.

Porém, o que, no medievo, era restrito aos monastérios e conventos, se estendeu, no século XV e XVI, pelo tecido social da sociedade, diversificando-se e assumindo novas técnicas e formas, conforme as preocupações políticas da época. Assim, essa arte de governar os homens, a partir desse momento, sob novos 
métodos e focos, multiplicou-se para domínios variados. De modo que como governar as crianças, como governar os pobres e mendigos, como governar o lar, os exércitos e as cidades, como governar o corpo e o espírito tornaram-se questões fundamentais ao longo do século XV e XVI, originando artes de governo variadas, arte pedagógica, arte política, arte econômica, e ocasionando uma verdadeira governamentalização da sociedade e de seus domínios.

A atitude crítica, conforme Foucault, emerge e desenvolve-se nesse contexto de governamentalização enquanto uma reação sustentada da interrogação do "como não ser governado?", "como deixar de ser governado assim, segundo esses critérios e princípios, por essas pessoas?". A crítica consiste numa prática social constituída como uma arte de não ser governado, questionamentos e apontamentos que visam colocar sob suspeita, recusar, limitar as formas de ser governado impostas (FOUCAULT, 1990, p. 4).

De acordo com Foucault, podemos observar o desenvolvimento da atitude crítica em três registros: 1) num domínio religioso e eclesiástico como crítica dos dogmas e interpretações segundo o seu respaldo nas Escrituras. Fornecerá a base e o impulso para a crítica histórica das fontes, da filologia e da hermenêutica, fundamentais para a constituição das ciências da história e da linguagem; 2) num domínio jurídico-político estatal como crítica dos fundamentos das leis, da legitimidade e dos limites do poder político e da soberania. Trata-se do tipo de questionamento que dará origem às doutrinas do Direito Natural e dos Direitos Humanos as quais oporão ao Estado e seus poderes direitos universais e imprescritíveis, aos quais todo governo e autoridade, não importa qual, que se trate do monarca, do magistrado, do educador, do pai de família, deverá se submeter; 3) Por último, o domínio do saber como crítica do poder e pretensão de verdade fundamentado na autoridade. Trata-se do questionamento e da nãosubmissão intelectual ao discurso da tradição e das autoridades reconhecidas e suas afirmações injustificadas e não-demonstradas. Temos aqui a filosofia e a ciência moderna enquanto formas de conhecimento e investigação baseada no exercício livre da razão e nas exigências de observação e experimentação. 
Para Foucault, é esse processo histórico que envolve a Bíblia, o direito e a ciência, a escritura, a natureza e a autoridade do dogmatismo que formará a atitude crítica moderna do Esclarecimento, enquanto exigência de autonomia e exercício livre da própria razão - sapere aude, o "ousa-te saber" kantiano.

Diferentemente de Habermas (1989), a crítica ou, se quiser, o agir comunicativo baseado no diálogo e na força do melhor argumento em contextos interativos, livres de coação, não é exterior, enquanto um domínio próprio, um sistema à parte da sociedade, "o mundo da vida" ou uma tipo diferente de racionalidade (comunicativa). O desenvolvimento histórico da crítica enquanto prática social e cultural ocorre no interior e nas margens do jogo, e contra ele, da governamentalização da sociedade, no feixe de relações estabelecidas concretamente e em domínios precisos entre saber e poder, um em relação a outro. Ela é imanente aos processos e instituições de poder e do agir estratégico porque é um enfrentamento dos seus efeitos de poder e de sua política de verdade, e não algo que se desenvolve separadamente, quase escondido, e que se deve preservar e manter puro e livre das coerções e colonizações do sistema e seus subsistemas estratégicos.

Desse ponto resulta que a crítica deve ser dirigida menos às instituições, que simbolizariam mais diretamente determinados tipos de exercício de poder, e mais às formas de racionalidade, pois a questão principal consiste em como as relações de poder são racionalizadas.

Para finalizar, contra as acusações de pós-modernismo e irracionalismo que, vez por outra, são lançadas contra Foucault, cabe assinalar que a história crítica da razão ou das formas e regimes de racionalidade não encontra, no filósofo francês, uma motivação condenatória ou de julgamento:

Devemos julgar a razão? Em minha opinião, nada seria mais estéril. Primeiro, porque o campo a ser trabalhado nada tem a ver com a culpa ou a inocência. Segundo, porque não tem sentido referir-se à razão como uma entidade contrária a não-razão. Por último, porque tal julgamento nos condenaria a representar o papel arbitrário e enfadonho do racionalista ou do irracionalista (FOUCAULT, 1995, p. 233). 
A despeito daqueles que tomaram, equivocadamente, seu trabalho como irracionalismo e negação da racionalidade moderna (BERMAN, 1986; HABERMAS, 2002), Foucault, na verdade, jamais enxergou nas relações entre racionalização e poder a morte da razão ou a razão como fonte da irracionalidade e violência humana. Sua história da razão trata, simplesmente, de análises históricas das formas de racionalidade - e suas transformações - empregadas em nossa sociedade. Como escreve o filósofo francês, "o respeito do racionalismo como ideal nunca deve impedir a análise das racionalidades realmente empregadas" (FOUCAULT, 2006, p.354).

Se a história e a crítica das formas de racionalidade produzem grande inquietação e incômodo é porque realizá-la produz efeitos e riscos similares aos causados quando se conta a história das religiões. Abala as certezas e o dogmatismo, ameaça poderes constituídos. O que, uma vez mais, exprime os vínculos muito íntimos entre razão e poder, entre verdade e poder (FOUCAULT, 2006, p. 384).

\section{Considerações finais}

Michel Foucault coloca sua empresa intelectual na esteira do pensamento crítico moderno, isto é, na problematização das relações entre racionalização e poder analisada a partir da diversidade de regimes de práticas históricas constituídas nas sociedades ocidentais.

Numa sociedade caracterizada pela expansão dos mecanismos de poder e das formas de sujeição individualizadoras e normalizantes, oriundas da gestão política da sociedade que se organiza sob o nexo saber poder, seu tratamento analítico da racionalidade nos sugere, ainda, que o papel premente de todo pensamento crítico é "vigiar os excessivos poderes da racionalidade política" (FOUCAULT, 1995, p. 233).

Excessos, aliás, como não cansou de tentar demonstrar a obra foucaultiana, que não se exprimem apenas nas formas totalitárias da racionalidade política ou na burocracia moderna, mas nos aspectos mais sutis e aparentemente desinteressados 
do uso da razão sobre a vida cotidiana mesma, na lida diária dos indivíduos com os especialistas e as instituições. Não seria exatamente esta uma das grandes contribuições de Foucault ao pensamento crítico? Desfamiliarizar os excessos da racionalidade e do poder na vida cotidiana.

Se há uma história da razão, em Foucault, ela é pensada e praticada como crítica histórica das formas de racionalidades naquilo que elas podem produzir, em termos de violência, exclusão e sujeição sobre a vida dos indivíduos como efeitos e excessos das relações, construídas na história do Ocidente, entre as estruturas de racionalidade e o exercício de poder. Daí que a primeira atitude da crítica tem ser a de "dessubjetivar a questão filosófica pelo recurso ao conteúdo histórico, libertar os conteúdos históricos pela interrogação sobre os efeitos de poder, conteúdos cuja verdade (de que, supostamente, derivam) é afetada por esses efeitos" (FOUCAULT, 2012, p. 66).

Certamente, sem as análises de Foucault sobre as formas de racionalidade, com os seus mecanismos de poder e sujeição que investem e atravessam a vida imediata e diária, estaríamos muito mais afastados de uma compreensão mais matizada e nuançada sobre os perigos da racionalidade.

\section{Referências}

ADORNO, T.; HORKHEIMER, M. A Dialética do Esclarecimento: fragmentos filosóficos. Rio de Janeiro: J. Zahar, 1985

BAUMAN, Zygmunt. Modernidade e holocausto. Rio de Janeiro: Zahar Editores, 1998

BERMAN, Marshall. Tudo o que é sólido desmancha no ar: a aventura da modernidade. São Paulo. Companhia das Letras, 1986.

BOUDON, Raymond. Towards a General Theory of Rationality, Bardwell Press, Oxford, 2009.

FOUCAULT, Michel. "Sobre a história da sexualidade". In. Microfísica do poder. Rio de Janeiro. Graal, 1979a, p.243-275. . "Nietzsche, a genealogia e a história". In Microfísica do poder. Rio de Janeiro. Graal, 1979b, p. 15-38.

. La impossible prisón. Barcelona, Anagrama, 1982

Graal, 1988.

História da sexualidade - a vontade de saber. Rio de Janeiro, História da sexualidade - o uso dos prazeres. Rio de Janeiro. Graal, 1984 
"O sujeito e o poder". In. DREYFUS, H. \& RABINOW, P. Michel Foucault, uma trajetória filosófica: para além do estruturalismo e da hermenêutica. Rio de Janeiro. Forense Universitária, 1995.

. Em defesa da sociedade - curso no College de France (1975-1976). São Paulo. Martins Fontes, 1999.

. Vigiar e Punir: o nascimento da prisão. Petrópolis. Vozes, 2004.

"Estruturalismo e pós-estruturalismo". In: Ditos \& Escritos:

Arqueologia das ciências e história dos sistemas de pensamento (vol. II) Tradução de Elisa Monteiro. Rio de Janeiro: Forense Universitária, 2005a

A vida: a Experiência e a Ciência. Ditos \& Escritos: Arqueologia das Ciências e História dos Sistemas de Pensamento (Vol. II). Rio de Janeiro. Forense Universitária, 2005b, p. 352-366.

. Ditos \& Escritos - Estratégias poder-saber (vol. IV). 2 ed. Rio de Janeiro: Forense Universitária, 2006.

. "O que são as Luzes?" In. Ditos \& Escritos: Arte, Epistemologia, Filosofia e História da medicina (vol. VII). Rio de Janeiro. Forense universitária, 2011, p 259-268.

. "O que é a crítica?" (Crítica e Aufklärung). Trad. Gabriela Borges, revisão Wanderson Nascimento, publicada no Bulletin de la Société française de Philosofie, vol. 82, n.2, p 35-63, abril-jun 1990, disponível em Espaço Michel Foucault - www. filoesco.unb.br/foucault, consultado em 12 novembro de 2018.

. Ditos \& Escritos - Segurança, penalidade e prisão (vol. VIII). Rio de Janeiro: Forense Universitária, 2012

. Ditos \& Escritos. Genealogia da ética, subjetividade e sexualidade (vol. IX). Rio de Janeiro. Forense universitária, 2014.

GIDDENS, Anthony. A constituição da sociedade. São Paulo. Martins Fontes, 2003. ILLOUZ, Eva. O amor nos tempos do capitalismo. Trad. Vera Ribeiro. Rio de Janeiro: Zahar, 2011.

HABERMAS, Jurgen. Consciência moral e agir comunicativo. Rio de Janeiro, Tempo Brasileiro, 1989.

2002.

O discurso filosófico da modernidade. São Paulo. Martins Fontes,

. A teoria do agir comunicativo: racionalidade da ação e racionalização social. São Paulo. WMF Martins Fontes, 2012.

HONNETH, Axel. Crítica Del Poder: Fases em la reflexión de uma Teoria Crítica de la sociedad. Madrid: Machado, 2009

MARTUCCELLI, Danilo. Sociologies de la modernité: L'itinéraire du XX siècle. Paris: Gallimard, 1999.

RITZER, George. The McDonaldization of society: an investigation into the changing character of contemporary social life. Newbury Park, California. Pine Forge Press, 1993.

TURNER, Bryan S. The Body and Society. Sage Pub. London, 1996.

WEBER, Max. Economia e Sociedade: fundamentos da sociologia compreensiva.

Vol. I. Brasília. UnB, 1994

. Ensayos sobre sociología de la religión. Madri, Taurus, 2001.

Recebido: $11 \mathrm{dez} .2018$ 
Aceito: 15 jan. 2019 